\title{
DRIVING DYNAMICS OF AN ELECTRIC VEHICLE WITH ELECTRONIC DIFFERENTIAL ASSISTED DRIVE
}

\author{
Juraj Madarás ${ }^{1}$ Martin Bugár ${ }^{1}$ Ján Danko \\ ${ }^{1}$ Institute of automotive mechatronics, Faculty of electrical engineering and information \\ technology, STU Bratislava, juraj.madaras@stuba.sk \\ ${ }^{2}$ Institute of transport technology and designing, Faculty of mechanical engineering, STU \\ Bratislava, jan.danko@stuba.sk
}

Keywords: electric vehicle, steering, simulation, differential

\begin{abstract}
The electric motor's features allow a large scale of possible drivetrain conceptions for electric vehicles. One of the most efficient conceptions is an electric vehicle with two electric machines which operates as an electronic differential. The main objective of this paper is to discuss the possibilities for the simulation of the driving dynamics of an electric vehicle during cornering. To control the vehicle's motion, driving demands and electric motors (PMSM), it is most suitable to use co-simulation in a MATLAB/Simulink ${ }^{\circledR}$ environment. The ability to control the engines (PMSM) during direction changes is demonstrated in the simulation results.
\end{abstract}

\section{INTRODUCTION}

The Electric motor is suitable for the propulsion of vehicles due to its torque characteristics, which are the same as the ideal torque characteristics of an internal combustion engine with a gearbox and clutch [2]. The efficiency of the conversion of electrical energy into mechanical work is nearly $90 \%$, and in the entire field of operating characteristics the efficiency is above $70 \%$, which is more than double the efficiency of the present best combustion engines [1]. Also, the possibility of recovering energy during regenerative braking predisposes electric motors to the task of propelling cars [3]. The compact size of electric motors allows engineers to design new powertrain conceptions.

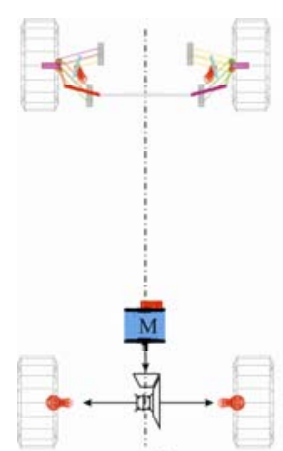

a.)

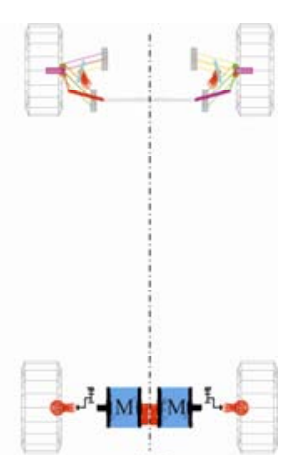

b.)

Figure 1: Electric vehicle drivetrain conceptions: a.) single central motor drive, b.) tandem motors with planetary gear sets 
This preferred layout in terms of spatial demands and provided performance entails the need for the speed control of the electric motors to achieve natural wheel rolling during vehicle cornering. Therefore, it is a substitute for the mechanical differential system using the appropriate control algorithms for electric motors. These control algorithms together with electric engines and the entire powertrain represent an electronic differential system, as can be seen in Fig.1.

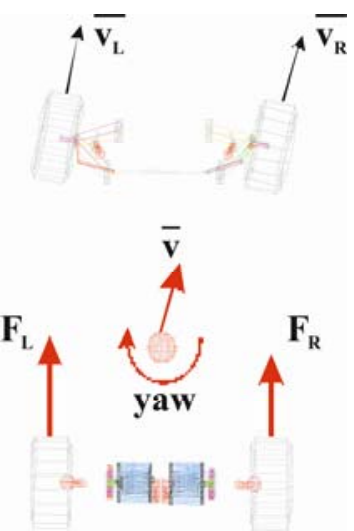

Figure 2: Electric vehicle drivetrain conceptions: a.) single central motor drive, b.) tandem motors with planetary gear sets

The electric motor control algorithm used during cornering of the vehicle, is based on Ackerman's steering geometry and the differential gear kinematics theory of the vehicle. It is necessary to know the cornering radius first, as it can be obtained from the steering geometry [1].

\section{MATHEMATICAL FORMULATION OF THE STEERING GEOMETRY}

To achieve the correct functionality of the electric motor control algorithm, it is necessary to derive the main relations which describe the vehicle's cornering motion [4].

In order to ensure an ideal rolling of the wheels during cornering, it is necessary for each wheel to describe a circle with a common center at the point 0 . In other words, all of the wheel axes must intersect at one point. Due to the fact that the rear wheels are fixed on the rear axle and aren't adaptive, and the situation is analogous for the front wheels, both wheel pairs must have the same rotation axis.

The front wheels must be rotated by angles $\alpha$ and $\beta$ for compliance with the abovedescribed conditions (Fig. 3). The theoretical cornering radius can be expressed based on the steering angles of the front wheels as follows:

$$
R_{0}=L \cdot \cot \beta+\frac{B_{0}}{2}=L \cdot \cot \alpha-\frac{B_{0}}{2}
$$




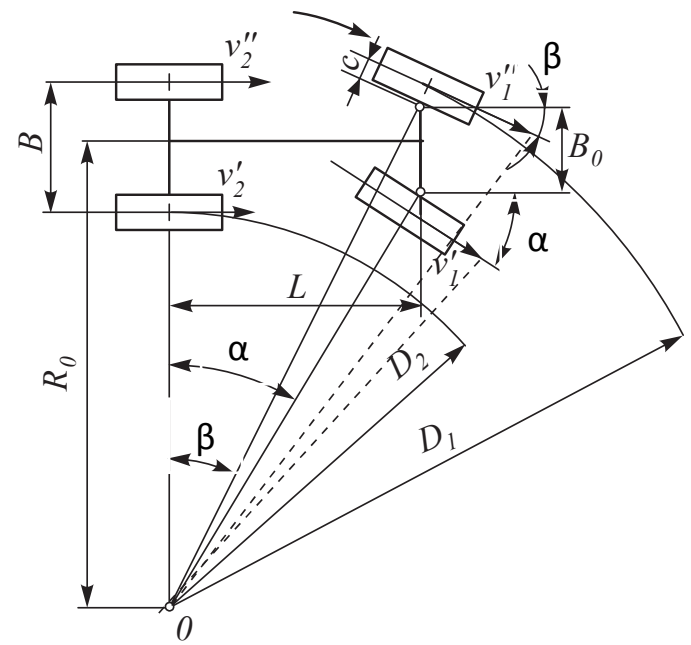

Figure 3: Steering geometry of a two axle, four wheel vehicle, where: $B$ - track width of the driven axle, BO - width of the steering axles, $L$ - wheelbase, $c$ - real center of cornering displacement, $\alpha$ angle displacement of the inner wheel, $\beta$ - angle displacement of the outer wheel, 0 -center of cornering, RO - theoretical cornering radius, D1 - outer trace distance, D2 - inner trace distance, $v 2^{\prime}, v 2^{\prime \prime}$ - vectors of the rear wheels' velocity, $v 1^{\prime}, v 1^{\prime \prime}-$ vectors of the front wheels' velocity.

For simplicity, it is possible to use the median angle of both wheels (Fig. 4) calculated from the angular displacement of the wheels (Fig. 3):

$$
\alpha_{S}=\frac{\alpha+\beta}{2}
$$

The distance between centre of rotation and vehicle's centre of gravity is given by:

$$
R_{0}=\frac{L}{\tan \alpha_{s}}
$$

For a simplified representation it is possible to reduce the vehicle model to a three-wheel replacement model as described in the Fig. 4.

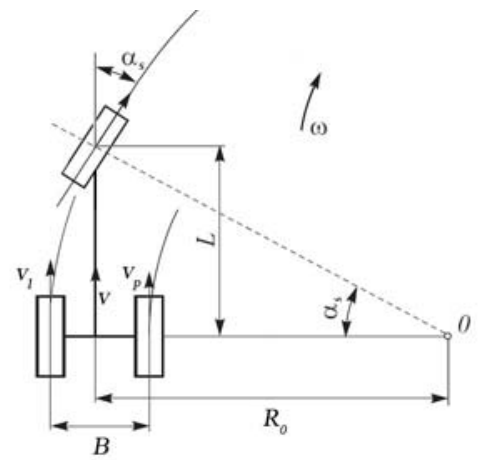


Figure 4: Three wheel replacement model of the vehicle during cornering.

Based on Fig. 4, the angular velocity equations of the left and right driven wheels can be derived based on the following equations. From the top view, the centres of both driven wheels of the vehicle are spinning with equal angular velocity about the point 0 .

$$
\omega=\frac{v}{R_{0}} \Rightarrow v=\omega \cdot R_{0}
$$

Both wheels have the same angular velocity about the point 0 , but different distances from the centre of rotation:

$$
\begin{aligned}
& v_{L}=\omega \cdot\left(R_{0}+\frac{B}{2}\right) \Rightarrow \omega_{L}=\frac{\omega \cdot\left(R_{0}+\frac{B}{2}\right)}{r_{d}} \\
& v_{R}=\omega \cdot\left(R_{0}-\frac{B}{2}\right) \Rightarrow \omega_{R}=\frac{\omega \cdot\left(R_{0}-\frac{B}{2}\right)}{r_{d}}
\end{aligned}
$$

From equations $(5,6)$ the peripheral velocity of the wheel centre in the longitudinal direction and the angular velocities of both wheels has been obtained.

Since the model will be controlled by the steering wheel, it is necessary to derive the median angle of both wheels from steering wheel angle:

$$
\alpha_{S}=\alpha_{s w} \cdot i_{s m}
$$

where: $\alpha_{S}$ - median angle of steered wheels, $\alpha_{S W}$-steering wheel angle, $i_{s m}$ - ratio between steering wheel and steered wheels.

\section{CASE STUDY AND SIMULATION RESULTS}

The conventional differential system allows the wheels to spins at different speeds. This condition is necessary when the vehicle drives in a curve. The external wheels describe a circumference of the driving radius that is larger than that of the internal wheels (Fig.2,3).

The geometric model proposed by Ackerman shown in Fig. 2 can be used. This model allows for the determination of the radius of rotation $\left(R_{O}\right)$ from the steering angle and in turn the angular speed values that each rear (traction) wheel have to adopt $\left(\omega_{1}, \omega_{2}\right)$.

The electronic differential has to take into account the difference in speed between the two driven wheels duringvehicle cornering. The system uses the vehicle's speed and steering angle as input parameters and calculates the required inner and outer wheel speeds, with the two wheels controlled independently by two PMSM electric motor/generators.

When the vehicle comes to the beginning of a curve, the control system applies a steering angle to the wheels. The electronic differential acts immediately on the two motors reducing the speed of the inner wheel, and increasing the angular velocity of the outer wheel.

Our designed simulation model of a vehicle driven using an electronic differential is divided into two parts [5]:

- Model of the vehicular and powertrain dynamics, including sensors and actuators, 
- Model of the electronic differential control system, including two electric motors.

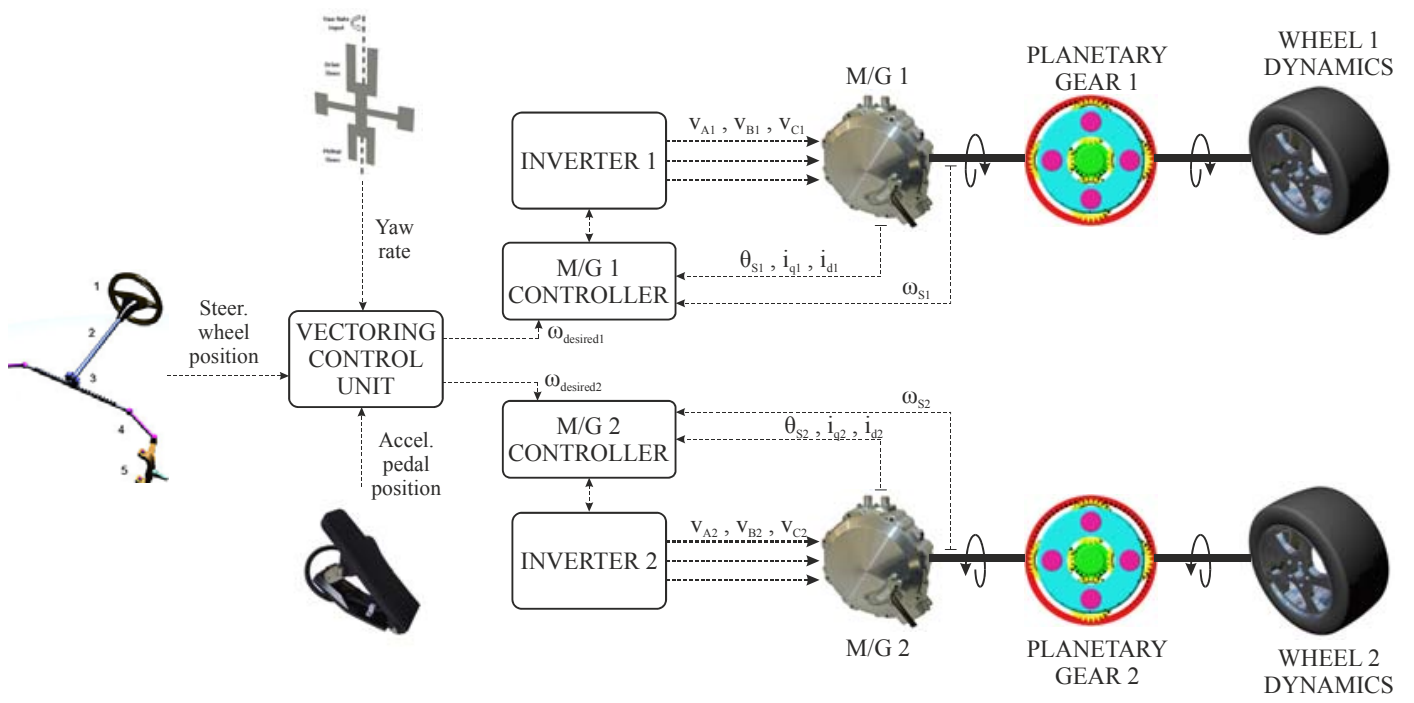

Figure 5: Proposed electric vehicle propulsion and control system schematic diagram [5]

Where: 1 -steering wheel, 2 - steering column, 3 - steering gearbox, 4 - tie rod, 5 - hub and bearing assembly with steering arm, $M / G 1$-electric motor/generator $1, M / G 2$-electric motor/generator 2, $v_{A 1}, v_{B 1}, v_{C 1}$-three phase electric power supply of $M G / 1, v_{A 2}, v_{B 2}, v_{C 1}$ - three phase electric power supply of $M G / 2, \omega_{S 1}$-angular velocity of the left wheel, $\omega_{S 2}-$ angular velocity of the right wheel, $\omega_{\text {desired } 1}-$ desired angular velocity of the left wheel, $\omega_{\text {desired } 1}-$ desired angular velocity of the right wheel, $\theta_{S 1}$-position sensor of $M / G 1, i_{q 1}$-current sensor of magnetic flux of $M / G 1, i_{d 1}-$ current flux sensor of $M / G 1, \theta_{S 2}$ - position sensor of $M / G 2, i_{q 2}$-current sensor of the magnetic flux of $M / G 2, i_{d 2}-$ current flux sensor of $M / G 2$.

The results of the co-simulation are several plotted time dependencies. For the vehicle model, the desired longitudinal velocity and the steering wheel angle has been prescribed (Fig. 7.).

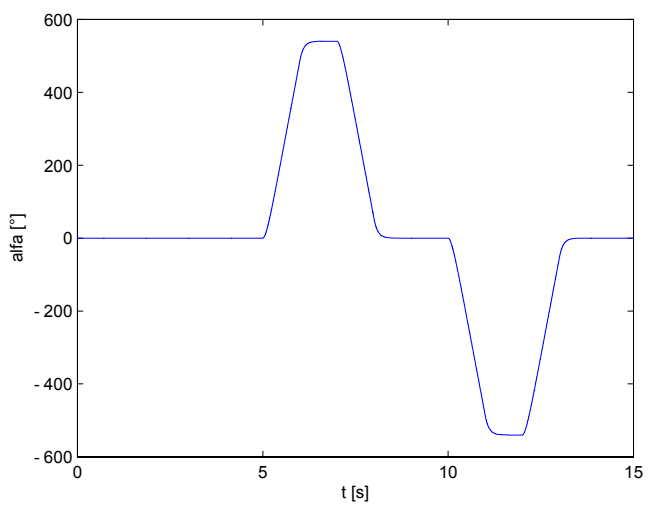

Figure 7: Desired angle of the steering wheel.

The angular velocity of the both electric motors during longitudinal motion was set to 104,5 rad. $\mathrm{s}^{-1}(1000 \mathrm{rpm})$ after a 1 second acceleration. 


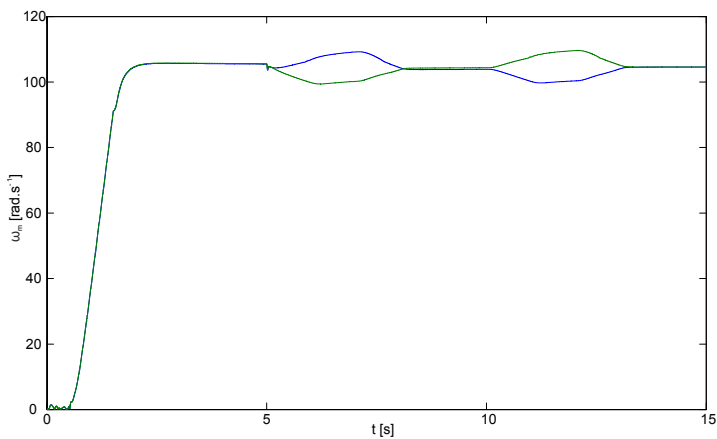

Figure 8: Angular velocities of the left (green) and right (blue) electric motors.

Fig. 8 shows the difference in the angular velocities of the electric motors during vehicle cornering, according to the angle of the steering wheel.

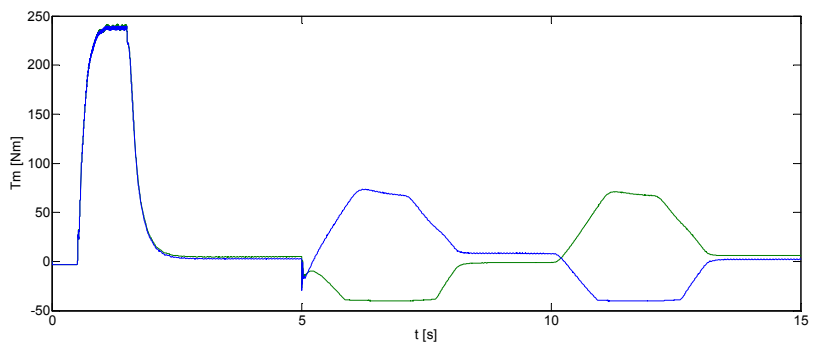

Figure 9: Output mechanical torques of the electric motors

The driving torques, presented in Fig. 9 show the response of the electric motors to the control algorithm during cornering.

The negative value of the mechanical torques at the beginning of the co-simulation is caused by the passive resistance of the electric motors (viscous and Coulomb friction). The negative value of the torque during cornering is given by the control algorithm; the electric motor is regenerating energy and retarding the inner wheel to reach the desired angular velocity (like a conventional vehicle with an electronic stability program).

\section{CONCLUSION}

Based on the mathematical dependences, anelectronic differential control system was designed. The functionality of the electronic differential control system was designed and simulated considering the ideal conditions of electric vehicle's movement. From the simulation modelresults were obtained which show the functionality of the designed electronic differential controlunder ideal driving conditions and neglecting the dynamic influences of the electric vehicle's dynamic motion during cornering. The control algorithm is based on the theoretical cornering radius calculation from the sensed angle of rotation of the steering wheel and the sensed longitudinal velocity of the vehicle calculated from the angular velocity sensors located on each wheel.Future research will be focused on the mathematical expression of electric vehicle cornering based on the calculation of the real cornering radius. The calculation of the value of the real cornering radius is based on the longitudinal and lateral slip characteristics of each tire during electric vehicle cornering. 


\section{REFERENCES}

[1] Danko, Ján - Magdolen, L’uboš - Masaryk, Michal - Bugár, Martin - Madarás, Juraj: Energy management system algorithms for the electric vehicle applications. In: Mechatronics 2013 : 10th International conference. 7 - 9 October 2013, Brno, Czech Republic. - Cham: Springer International Publishing, 2014. - ISBN 978-3-319-02293-2. S. 25-31

[2] Matej, Juraj - Danko, Ján - Šotník, Ján - Ferencey, Viktor: Analýza energetických tokov v hybridných pohonoch motorových vozidiel. In: KOKA 2006. 37. Mezinárodní konference kateder a pracovišt' spalovacích motorů českých a slovenských vysokých škol: Sborník abstraktů a př́íspěvků. - Praha: Česká zemědělská univerzita v Praze, 2006. - ISBN 80213-1510-5. - nestr.

[3] Bigoš P. - Puškár, M. - Kopas, M.:Design of Mechatronic System Specified for Feedback Required in Development of Combustion Engines. Procedia Engineering. Volume 48, 2012, p. 30-34. ISSN 1877-7058.

[4] R. Rajamani: Vehicle Dynamics and Control. Springer eBook Collection, Engineering [Dig. Serial], Springer- 11647 [Dig. Serial], Boston, MA

[5] Ferencey, Viktor - Madarás, Juraj - Bugár, Martin: Modeling of Energy and Powertrain System of the Electric Vehicle. In: Transport Means 2013: 17th International Conference. Kaunas, Lithuania, October 24-25, 2013. - Kaunas: University of Technology, 2013. ISBN 1822-296X. 